\title{
Bertrand Pricing Games under Differentiated Products and Distinct Cost Condition
}

\author{
Zhi-Gang WANG \\ School of Economy and Management, Wuhan Institute of Physical Education, Wuhan, 430079, \\ Hubei, China \\ wzg771102@163.com
}

Keywords: Bertrand Game, Cooperative Pricing, Equal Profit Curve.

\begin{abstract}
Under differentiated products and distinct cost condition, companies will not price at marginal cost, therefore they can achieve positive profits. Bertrand paradox can be solved to some extent. On the basis of price competition, companies can adopt price cooperation to improve their profit. With equal profit curve, we can observe the differences of increased profits under different cooperative patterns, which can help companies to improve the cooperative patterns and find better cooperative pattern.
\end{abstract}

\section{Introduction}

In Bertrand paradox, there are two manufacturers in the market who compete by price but not output. In the game, there is only one Nash equilibrium, in which the price of the two manufacturers equal to their marginal cost and each manufacturer get no profit. Since oligopolistic market and perfect competitive market are quite different, economist Bertrand proved that since there only two manufacturers in the market, perfect competition can be achieved totally. That is so called Bertrand paradox. There are four assumptions for Bertrand Model: (1) There are two oligopoly manufacturers in the market, producing homogenous products. The market demand is $Q=D(P)$; (2) The marginal cost of production is the same for these two manufacturers, and no fixed cost; (3) Manufacturers compete only one time, and make price decision at the same time; (4) There is no other manufacturers entering the market. To solve Bertrand Paradox, we need to change the assumption of the model. In this paper, we change the assumptions of homogenous products and the same cost for these two manufacturers and discuss the equilibrium under new assumptions. In addition, we discuss the possibility of cooperation between these two manufacturers with equal profit curve which is developed in this paper.

\section{The Model}

We assume there are two manufacturers, manufacturer one and manufacturer two. They produce similar but differential products. The price of their products are $P_{1}$ and $P_{2}$. Therefore the products of these two manufacturers can substitute each other but not completely substitute. The demand functions of these two manufacturers are $q_{1}=q_{1}\left(P_{1}, P_{2}\right)=a_{1}-b_{1} P_{1}+d_{1} P_{2}$ and $q_{2}=q_{2}\left(P_{1}, P_{2}\right)=a_{2}-b_{2} P_{2}+d_{2} P_{1}$. In the functions, $d_{1}, d_{2}>0$, which refers to the substitution coefficient, indicating the extent that the products of these two manufacturers substitute each other. In addition, we assume there are no fixed cost for these two manufacturers, and the marginal cost of them are $c_{1}$ and $c_{2}$ separately. They make their price decision at the same time.

$u_{1}$ and $u_{2}$ are used to represent the profits of these two manufacturers, which are the function of their price.

$$
\begin{aligned}
& u_{1}=u_{1}\left(P_{1}, P_{2}\right)=P_{1} q_{1}-c_{1} q_{1}=\left(P_{1}-c_{1}\right)\left(a_{1}-b_{1} P_{1}+d_{1} P_{2}\right) \\
& u_{2}=u_{2}\left(P_{1}, P_{2}\right)=P_{2} q_{2}-c_{2} q_{2}=\left(P_{2}-c_{2}\right)\left(a_{2}-b_{2} P_{2}+d_{2} P_{1}\right)
\end{aligned}
$$


Ordering $\frac{\partial u_{1}}{\partial P_{1}}=0$, we get the response curve of manufacturer one as follow.

$$
P_{1}=R_{1}\left(P_{2}\right)=\frac{1}{2 b_{1}}\left(a_{1}+b_{1} c_{1}+d_{1} P_{2}\right)
$$

Ordering $\frac{\partial u_{2}}{\partial P_{2}}=0$, we get the response curve of manufacturer two as follow.

$$
P_{2}=R_{2}\left(P_{1}\right)=\frac{1}{2 b_{2}}\left(a_{2}+b_{2} c_{2}+d_{2} P_{1}\right)
$$

Solving above questions, we get equilibrium price as follow.

$$
\left\{\begin{array}{l}
P_{1}^{*}=\frac{d_{1}}{4 b_{1} b_{2}-d_{1} d_{2}}\left(a_{2}+b_{2} c_{2}\right)+\frac{2 b_{2}}{4 b_{1} b_{2}-d_{1} d_{2}}\left(a_{1}+b_{1} c_{1}\right) \\
P_{2}^{*}=\frac{d_{2}}{4 b_{1} b_{2}-d_{1} d_{2}}\left(a_{1}+b_{1} c_{1}\right)+\frac{2 b_{1}}{4 b_{1} b_{2}-d_{1} d_{2}}\left(a_{2}+b_{2} c_{2}\right)
\end{array}\right.
$$

At the equilibrium price, the output and profits of these two manufacturers are as follow.

$$
\begin{aligned}
& q_{1}^{*}=\frac{b_{1}\left\{d_{1}\left(a_{2}+b_{2} c_{2}\right)+\left[2 a_{1} b_{2}+c_{1}\left(d_{1} d_{2}-2 b_{1} b_{2}\right)\right]\right\}}{4 b_{1} b_{2}-d_{1} d_{2}} \\
& q_{2}^{*}=\frac{b_{2}\left\{d_{2}\left(a_{1}+b_{1} c_{1}\right)+\left[2 a_{2} b_{1}+c_{2}\left(d_{1} d_{2}-2 b_{1} b_{2}\right)\right]\right\}}{4 b_{1} b_{2}-d_{1} d_{2}} \\
& u_{2}^{*}=b_{2}\left\{\frac{d_{2}\left(a_{1}+b_{1} c_{1}\right)+\left[2 a_{2} b_{1}+c_{2}\left(d_{1} d_{2}-2 b_{1} b_{2}\right)\right]}{4 b_{1} b_{2}-d_{1} d_{2}}\right\}^{2}=\frac{q_{2}^{* 2}}{b_{2}}=b_{2}\left(P_{2}^{*}-c_{2}\right)^{2} \\
& u_{1}^{*}=b_{1}\left\{\frac{d_{1}\left(a_{2}+b_{2} c_{2}\right)+\left[2 a_{1} b_{2}+c_{1}\left(d_{1} d_{2}-2 b_{1} b_{2}\right)\right]}{4 b_{1} b_{2}-d_{1} d_{2}}\right\}^{2}=\frac{q_{1}^{* 2}}{b_{1}}=b_{1}\left(P_{1}^{*}-c_{1}\right)^{2}
\end{aligned}
$$

\section{The Price under Cooperation Condition}

When competing, the $P_{1}^{*}$ and $P_{2}^{*}$ are the equilibrium price of these two manufacturers, which means each manufacturer can not enhance its own profit by only changing its own price. The price in the market is stable. At this price, the profits of these two manufacturers are not maximized, for they can collude to raise their price in order to increase their profits. Following, we intend to prove the process.

$$
u_{1}+u_{2}=\left(P_{1}-c_{1}\right)\left(a_{1}-b_{1} P_{1}+d_{1} P_{2}\right)+\left(P_{2}-c_{2}\right)\left(a_{2}-b_{2} P_{2}+d_{2} P_{1}\right)
$$

Ordering $\frac{\partial\left(u_{1}+u_{2}\right)}{\partial P_{1}}=0$ and $\frac{\partial\left(u_{1}+u_{2}\right)}{\partial P_{2}}=0$, we get the prices of manufacturers as follow. 


$$
\begin{aligned}
& P_{1}=\frac{d_{1} c_{1}+2 b_{2} P_{2}-a_{2}-b_{2} c_{2}}{d_{1}+d_{2}} \\
& P_{2}=\frac{d_{2} c_{2}+2 b_{1} P_{1}-a_{1}-b_{1} c_{1}}{d_{1}+d_{2}}
\end{aligned}
$$

Solving above equations, we get the optimal prices of these two manufacturers as follow.

$$
\begin{aligned}
& P_{1}^{* * *}=\frac{2 b_{2}\left(a_{1}+b_{1} c_{1}-d_{2} c_{2}\right)+\left(d_{1}+d_{2}\right)\left(a_{2}+b_{2} c_{2}-d_{1} c_{1}\right)}{4 b_{1} b_{2}-\left(d_{1}+d_{2}\right)^{2}} \\
& P_{2}^{* * *}=\frac{2 b_{1}\left(a_{2}+b_{2} c_{2}-d_{1} c_{1}\right)+\left(d_{1}+d_{2}\right)\left(a_{1}+b_{1} c_{1}-d_{2} c_{2}\right)}{4 b_{1} b_{2}-\left(d_{1}+d_{2}\right)^{2}}
\end{aligned}
$$

at these prices, the outputs, marginal profits and profits of these two manufacturers are as follow.

$$
\begin{aligned}
& q_{1}^{* *}=\frac{2 a_{1} b_{1} b_{2}+\left(d_{1}+d_{2}\right)\left(b_{1} b_{2} c_{2}-a_{1} d_{2}-c_{2} d_{1} d_{2}\right)+2 b_{1} c_{1}\left(d_{1} d_{2}-b_{1} b_{2}\right)+a_{2} b_{1}\left(d_{1}-d_{2}\right)}{4 b_{1} b_{2}-\left(d_{1}+d_{2}\right)^{2}} \\
& q_{2}^{* *}=\frac{2 a_{2} b_{1} b_{2}+\left(d_{1}+d_{2}\right)\left(b_{1} b_{2} c_{1}-a_{2} d_{1}-c_{1} d_{1} d_{2}\right)+2 b_{2} c_{2}\left(d_{1} d_{2}-b_{1} b_{2}\right)+a_{1} b_{2}\left(d_{2}-d_{1}\right)}{4 b_{1} b_{2}-\left(d_{1}+d_{2}\right)^{2}} \\
& P_{1}^{* *}-c_{1}=\frac{2 b_{2}\left(a_{1}-b_{1} c_{1}-d_{2} c_{2}\right)+\left(d_{1}+d_{2}\right)\left(a_{2}+b_{2} c_{2}+c_{1} d_{2}\right)}{4 b_{1} b_{2}-\left(d_{1}+d_{2}\right)^{2}} \\
& P_{2}^{* *}-c_{2}=\frac{2 b_{1}\left(a_{2}-b_{2} c_{2}-d_{1} c_{1}\right)+\left(d_{1}+d_{2}\right)\left(a_{1}+b_{1} c_{1}+c_{2} d_{1}\right)}{4 b_{1} b_{2}-\left(d_{1}+d_{2}\right)^{2}} \\
& u_{1}^{* *}=\left(P_{1}^{* *}-c_{1}\right) q_{1}^{* *}=\frac{\left[2 a_{1} b_{1} b_{2}+\left(d_{1}+d_{2}\right)\left(b_{1} b_{2} c_{2}-a_{1} d_{2}-c_{2} d_{1} d_{2}\right)+2 b_{1} c_{1}\left(d_{1} d_{2}-b_{1} b_{2}\right)+a_{2} b_{1}\left(d_{1}-d_{2}\right)\right]}{\left[4 b_{1} b_{2}-\left(d_{1}+d_{2}\right)^{2}\right]^{2}} \\
& u_{2}^{* *}=\left(P_{2}^{* *}-c_{2}\right) q_{2}^{* *}=\frac{\left[2 a_{2} b_{1} b_{2}+\left(d_{1}+d_{2}\right)\left(b_{1} b_{2} c_{1}-a_{2} d_{1}-c_{1} d_{1} d_{2}\right)+2 b_{2} c_{2}\left(d_{1} d_{2}-b_{1} b_{2}\right)+a_{1} b_{2}\left(d_{2}-d_{1}\right)\right]}{\left[4 b_{1} b_{2}-\left(d_{1}+d_{2}\right)^{2}\right]^{2}}
\end{aligned}
$$

Above results shows when manufacturers raise the prices from $P_{1}^{*}$ and $P_{2}^{*}$ to $P_{1}^{* *}$ and $P_{2}^{* *}$, the profits of these manufacturers will rise from $u_{1}^{*}$ and $u_{2}^{*}$ to $u_{1}^{* *}$ and $u_{2}^{* *}$. However, the $P_{1}^{* *}$ and $P_{2}^{* *}$ are not equilibrium prices, which means any manufacturer can enhance its own profit by only changing its own price. Therefore, when manufacturers do not cooperate with each other, the market price will stabilize at $P_{1}^{*}$ and $P_{2}^{*}$. When they collude to enhance the prices, the market prices will be above $P_{1}^{*}$ and $P_{2}^{*}$. In fact, on the base of $P_{1}^{*}$ and $P_{2}^{*}$, they can enhance their profits by raising the price at the same time. And the $P_{1}^{* *}$ and $P_{2}^{* *}$ can maximize the total profits of them. 


\section{The Geometric Analysis of Price Cooperation between Manufacturers}

Since these two manufacturers can improve their profits by enhance their prices, we can analysis the benefit of price cooperation in a geometric way.

\section{Response Curve}

From the response functions of these two manufacturers, we can get the response curves of them as showed in following figure.

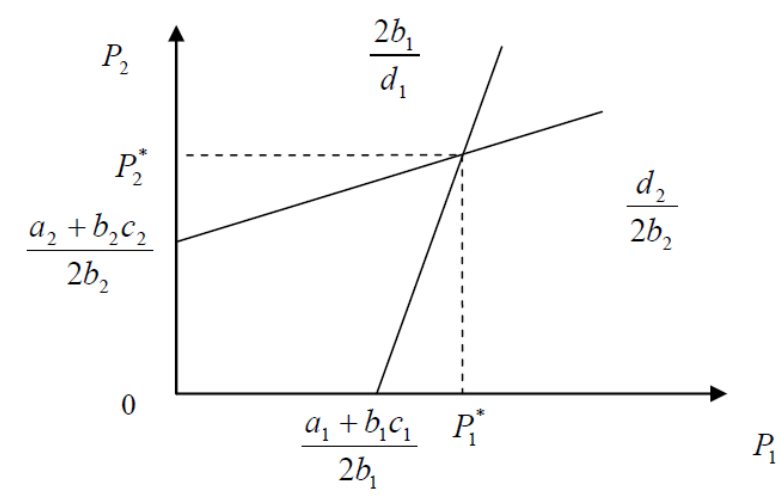

Fig. 1. Response Curve

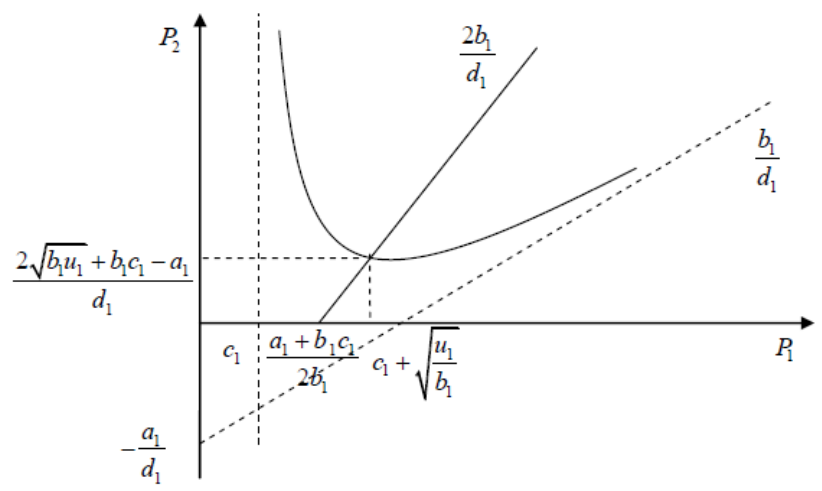

Fig. 2. Equal Profit Curve of Manufacturer one

The response curve of manufacturer one is a line with $\frac{a_{1}+b_{1} c_{1}}{2 b_{1}}$ as its intercept in horizontal axis and $\frac{2 b_{1}}{d_{1}}$ as its slop. The response curve of manufacturer two is a line with $\frac{a_{2}+b_{2} c_{2}}{2 b_{2}}$ as its intercept in vertical axis and $\frac{2 b_{1}}{d_{1}}$ as its slop. Response curve shows, given the price of another manufacturer, the price which can maximize the profit of this manufacturer. The interception of these two response curves are equilibrium price $P_{1}^{*}$ and $P_{2}^{*}$. At this point, each manufacturer can not enhance its own profit by only changing its own price, hence its is a equilibrium point.

\section{Equal Profit Curve}

$$
u_{1}=\left(P_{1}-c_{1}\right)\left(a_{1}-b_{1} P_{1}+d_{1} P_{2}\right)
$$

Above function is the profit function of manufacturer one. We can regard it as the relationship between $P_{1}$ and $P_{2}$ at a certain profit level. With transformation, we get the equal profit function of manufacturer one as follow.

$$
P_{2}=\frac{b_{1}}{d_{1}}\left(P_{1}-c_{1}\right)+\frac{u_{1}}{d_{1}\left(P_{1}-c_{1}\right)}+\frac{b_{1} c_{1}-a_{1}}{d_{1}}
$$

Above equation is the equal profit function of manufacturer one, which represent all the possible combination of $P_{1}$ and $P_{2}$ to achieve a certain $u_{1}$. Based on the equal profit function of manufacturer one, we can draw the equal profit curve of manufacturer one as follow.

Above figure shows that the equal profit curve of manufacturer one is a $U$ shape curve with $P_{1}=c_{1}$ and $P_{2}=-\frac{a_{1}}{d_{1}}+\frac{b_{1}}{d_{1}} P_{1}$ as its asymptotic lines and with $\left(c_{1}+\sqrt{\frac{u_{1}}{b_{1}}}, \frac{2 \sqrt{b_{1} u_{1}}+b_{1} c_{1}-a_{1}}{d_{1}}\right)$ as its vertex. The equal profit curve of manufacturer one has following features. 
(1) The higher the equal profit curve, the higher profit of manufacturer.

(2) The connection of the vertex of all the equal profit curve is the response curve of the manufacturer.

(3) Given $P_{2}$, the optimal profit can be achieved by manufacturer one is the equal profit curve which tangents to $P_{2}$, its cut-off point be the vertex of the equal profit curve.

(4) The area above equal profit curve is the cooperation area of manufacturer one, that is taking the curve as the boundary, manufacturer one can enhance its profit by cooperating with another manufacturer within this area. However, the area below this curve is the non cooperation area, which means taking the curve as the boundary, manufacturer one can not enhance its own profit by cooperating with another manufacturer within this area.

\section{The Price Cooperation between Manufacturers}

Following, we put the equal profit curves of manufacturer one and manufacturer two together to discuss the price cooperation of these two manufacturers.

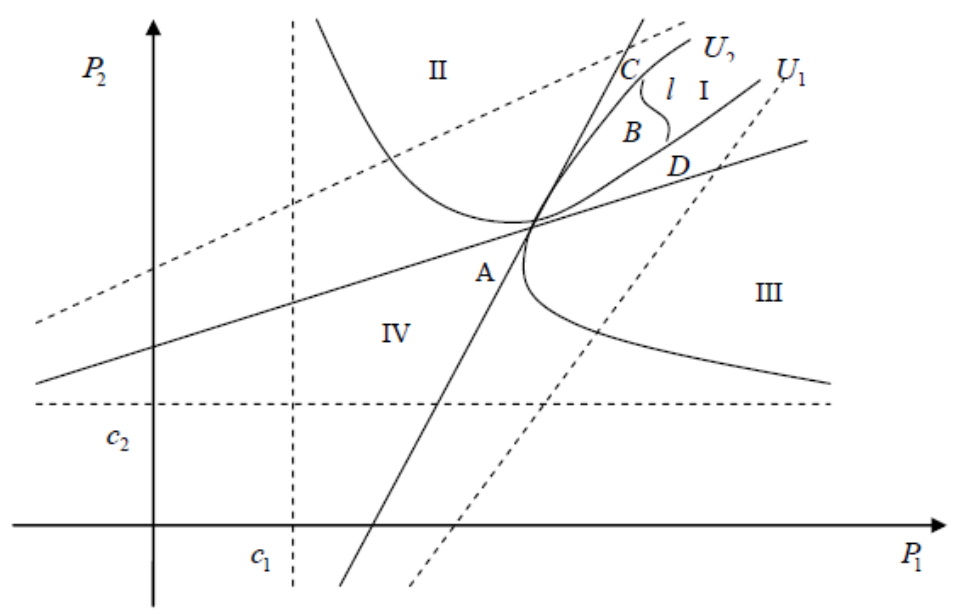

Fig. 3. The Price Cooperation of These Two Manufacturers

The point $\mathrm{A}$ in the figure is the intersection of the response curves of these two manufacturers. At this point, each manufacturer can not increase its profit by only changing its own price. When manufacturers do not cooperate with each other, the market reaches equilibrium. However, the equilibrium at this point is not Pareto optimal, for at least one manufacturer's profit can be increased by changing their prices. Suppose the equal profit curve of manufacturer one, which crosses the equilibrium point, is $U_{1}$, and the equal profit curve of manufacturer two, which crosses the equilibrium point, is $U_{2} . U_{1}$ and $U_{2}$ divide the figure into four areas, I, II, III and IV. Beginning with point $A$, the cooperation within area I can improve both the profits of these two manufacturers. If the price cooperation falls into area II, the profit of manufacturer one will be increased but the profit of manufacturer two will be decreased. If the price cooperation falls into area III, the profit of manufacturer one will be decreased but the profit of manufacturer two will be increased. If the price cooperation falls into area $\mathrm{IV}$, the profits of both manufacturers will be reduced. Hence only area $\mathrm{I}$ is the possible cooperation area for these two manufacturers, yet areas II ,III and IV are non cooperation areas for them.

Based on the market equilibrium, these two manufacturers can collude to increase the price to enhance their profits. Although the possible price cooperation within area I have much quantity, not all of them are Pareto optimal. Only the cut-off points of the manufacturers' equal profit curves are Pareto optimal, for Pareto improvement can not be achieved at these cut-off points. We connect the cut-off points to form curve $l$, which falls into area I with $C$ and $D$.

The best cooperation should lie at curve $l$, for the cooperation at this position have the best 
efficiency. All the points out of curve $l$ have the possibility of make Pareto improvement, which means at least one manufacturer's profit can be increased by changing their prices. The cooperation among line $l$ has the best efficiency, but the revenue sharing at different points in line $l$ is different. The closer to $C$, the more increased profit for manufacturer one and the less increased profit for manufacturer two. The closer to $D$, the more increased profit for manufacturer one and the less increased profit for manufacturer two. The point where the cooperation can be achieved will determined by the bargaining power of them.

Although the points among curve $l$ are all Pareto optimal, there is a point where the overall optimization can be achieved. At this point, the total profits of these two manufacturers are maximized. We use $B$ to represent this point. The sum of these two manufacturers' profits is maximized, which is the result $\left(P_{1}^{* *}, P_{2}^{* *}\right)$ we have got.

\section{Conclusion}

In Bertrand pricing model, if the hypothesis of homogeneous products and undifferentiated cost are changed, manufacturers can reach equilibrium price through competition to achieve their profits. At equilibrium price, each manufacturer can not increase its own profit by only changing its own price. Under non-cooperation game, the market reaches at equilibrium.

If the manufacturers can cooperate with each other, based on equilibrium prices their profits can be increased by raising their prices together. Although the possible price cooperation is much, some of them are Pareto optimal and some are not. Different price cooperation results in the different benefits sharing among the manufacturers.

Base on Bertrand pricing model to analysis the effect of price cooperation, this paper develops equal profit curve to analysis the equilibrium and the benefits of price cooperation in a geometric way.

\section{References}

[1] Boccard, N., Wauthy, X. Bertrand competition and Cournot outcomes: further results[J]. Economics Letters, 2000, 68: 279-285.

[2] Davidson, C., R. J. Deneckere. Horizontal mergers and collusive behavior[J]. International Journal of Industrial Organization, 1984, 2:117-32.

[3] De Francesco, Massimo A. On a Property of Mixed Strategy Equilibria of the Pricing Game[J]. Economics Bulletin, 2003, 30(4): 1-8.

[4] Dixon, Huw. Approximate Bertrand Equilibria in a Replicated Industry[J]. Review of Economic Studies, 1987, 54(1): 47-62.

[5] Kreps, D., J. Sheinkman. Quantity precommitment and Bertrand competition yields Cournot outcomes[J]. Bell Journal of Economics, 1983, 14: 326-337. 